\title{
Comprehensive analysis of surface integrity modification of ball-end milled Ti-6Al-4V surfaces through vibration-assisted ball burnishing
}

\author{
R. Jerez-Mesa ${ }^{\mathrm{a}, *}$, J.A. Travieso-Rodríguez ${ }^{\mathrm{b}}$, Y. Landon ${ }^{\mathrm{c}}$, G. Dessein ${ }^{\mathrm{d}}$, J. Lluma-Fuentes ${ }^{\mathrm{e}}$, \\ V. Wagner ${ }^{\mathrm{f}}$ \\ ${ }^{a}$ Universitat de Vic - Universitat Central de Catalunya, Facultat d'Enginyeries, C. de la Laura, 13, 08500 Vic, Spain \\ ${ }^{\mathrm{b}}$ Universitat Politècnica de Catalunya, Escola d'Enginyeria de Barcelona Est., Mechanical Engineering Department, Av. Eduard Maristany 10-14, 08019, Barcelona, Spain \\ ${ }^{\mathrm{c}}$ Université de Toulouse III Paul Sabatier, Institut Clément Ader, 3 Rue Caroline Aigle, 31400 Toulouse, France \\ d École National d'Ingénieurs de Tarbes, Laboratoire Génie de Production, 47 Av. d'Azereix, 65000, Tarbes, France \\ ${ }^{\mathrm{e}}$ Universitat Politècnica de Catalunya, Escola d'Enginyeria de Barcelona Est., Material Science and Metallurgical Engineering Department, Av. Eduard Maristany 10-14, \\ 08019, Barcelona, Spain \\ ${ }^{\mathrm{f}}$ École National d'Ingénieurs de Tarbes, Laboratoire Génie de Production, 47 Av. d'Azereix, 65000, Tarbes, France
}

\section{A R T I C L E I N F O}

Associate Editor: E. Budak

\section{Keywords:}

Vibration-assisted ball burnishing

Surface integrity

Surface texture

Residual stress

Hardness

Titanium

\begin{abstract}
A B S T R A C T
This paper is an experimental research about the mechanical effects on Ti-6Al-4V surfaces treated with an ultrasonic vibration-assisted ball burnishing process. Its aim is to define the process parameters to achieve the best surface integrity on the target workpiece, as well as identifying the effects caused by the introduction of vibrations as a means of assistance. A Taguchi orthogonal array including five factors (preload, number of passes, feed velocity, strategy and original surface texture) was applied to perform the process on ball-end milled surfaces. A comprehensive analysis of the effects was performed, by considering in depth three different facets of surface integrity, namely, topology, residual stress and hardness. Hence the extensive result datasets presented in this paper, which deliver an exhaustive description of the process effects by combining a triple approach in the results analysis section. The effect of vibrations is proved positive to enhance the texture as long as the original surface is not characterized by $S_{\mathrm{q}}>2 \mu \mathrm{m}$. Furthermore, only the preload and number of passes influence the results. In terms of residual stress, all parameters are influential in the results, especially the burnishing strategy, through which a specific direction can be reinforced. Finally, the burnishing operation proves to modify the hardness of deep layers down to $0.5 \mathrm{~mm}$, applying the vibration-assisted process. The main conclusion derived from these works is a technical recommendation to treat the Ti-6Al-4 V surface through the process, aiming to find a balanced comprehensive surface integrity enhancement.
\end{abstract}

\section{Introduction}

Metallic parts used in different industrial applications are predominantly shaped from raw materials through machining routines. Although chip removal processes are nowadays highly reliable to obtain parts with proper surface characteristics, surface engineering can still be enhanced by developing alternative finishing methods. Tailor-made surface integrity on workpieces is determinant to optimize product performance, and maximize the longevity and reliability of engineering parts. For instance, about $56 \%$ of catastrophic failures in turbine blades are caused by cracks initiated in positively stressed machined surfaces under high-frequency fatigue regimes, which can be prevented with adequate finishing treatments after machining, according to Prevéy et al., (2002).

Surface integrity management is remarkably important when special alloys are used to manufacture relevant and complex parts such as turbine blades, landing gears, molds and dies for upsetting operations, etc. This kind of parts are often manufactured through 3 or 5 axis

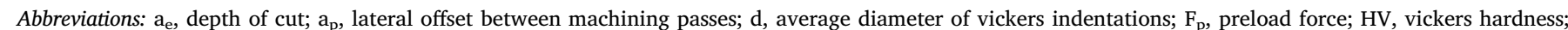

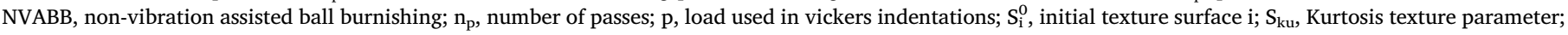

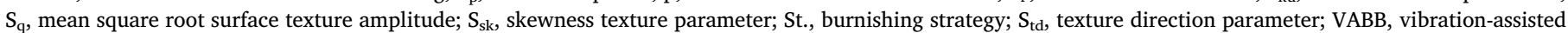
ball burnishing; $\mathrm{v}_{\mathrm{C}}$, cutting spVed; $\mathrm{v}_{\mathrm{f}}$, veed velocity

* Corresponding author.

E-mail addresses: ramon.jerez@uvic.cat (R. Jerez-Mesa), antonio.travieso@upc.edu (J.A. Travieso-Rodríguez), yann.landon@univ-tlse3.fr (Y. Landon), gilles.dessein@enit.fr (G. Dessein), jordi.lluma@upc.edu (J. Lluma-Fuentes), vincent.wagner@enit.fr (V. Wagner). 


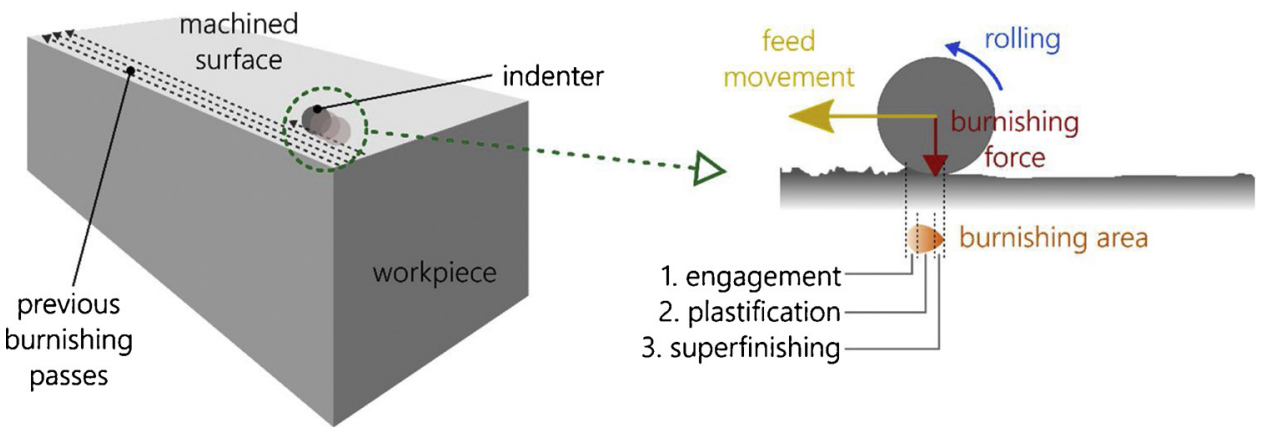

Fig. 1. Schematic representation of the ball burnishing process.

machining with the aid of successive adjacent passes of hemispherical tools, deriving in surfaces formed of periodic repetitions of peaks and valleys. Furthermore, advanced materials such as titanium or nickel alloys pose high difficulty towards preserving surface integrity after machining, as note numerous authors such as Ulutan and Ozel, (2011). In this context, the ball burnishing process (Fig. 1) -a finishing operation performed by plastic deformation of the target surface by means of a ball that rolls over the surface irregularities to compress them (Travieso-Rodriguez et al., 2011) -, can contribute to improve the surfaces of industrial parts, as show the works of several authors such as Lee and Loh (1996) or Shiou and Chen, (2003). The process is known for attaining a comprehensive surface improvement in terms of texture, residual stress and hardness, as well as for being easily maneuverable (Chomienne et al., 2016). Furthermore, it has proved to deliver better results in terms of surface roughness, residual stress and hardness of objective surfaces, when compared to other processes longer extended in the manufacturing industry such as laser shock peening (Altenberger et al., 2012), electro-polishing or shot peening (Shepard et al., 2004). Hence the motivation of this paper to increase the knowledge related to ball burnishing, especially in its assisted version applied to the Ti-6Al$4 \mathrm{~V}$ alloy.

Regarding vibration assistance, it has been identified as highly positive in numerous applications, such as machining (Shepard et al., 2004), and bulk plastic deformation processes (Huang et al., 2009). The advantage delivered by vibrations can be interpreted from different approaches. In the case of vibration-assisted ball burnishing (VABB), acoustoplasticity constitutes the main physical frame to understand the implications of the process on the material. Acoustoplasticity is the reduction of the quasi-static stress required to deform a material by the simultaneous propagation of waves across its lattice (Blaha and Langenecker, 1955), while residual hardening is observed on the target materials after vibration irradiation (Langenecker, 1966). For that reason, it is considered that it can benefit the ball burnishing process.

VABB has been previously studied by other researchers. A $2-\mathrm{kHz}$ vibration-assisted tool developed by Gomez-Gras et al. (2015) was successfully tested on a G10380 steel (Travieso-Rodriguez et al., 2015a) and A92017-T4 aluminum (Travieso-Rodriguez et al., 2015b) alloys, concluding that medium-frequency vibration assistance leads to a further improvement of roughness and residual hardening when compared with a conventional ball burnishing process. Higher frequencies have been tested by other researchers such as Huuki and Laakso, 2013, proving the positive effect of $20-\mathrm{kHz}$ VABB on the surface roughness, out-of-roundness, and hardness of turned 34CrNiMo6-M tempering steel, and, later, on 6082-T6 aluminum and S355J2 structural steel specimens. The Ti-6Al-4 V material, which is the target of this paper, was tested by Bozdana et al. (2005) with a $20-\mathrm{kHz}$ vibration-assisted hydrostatic burnishing tool, concluding that roughness could be improved to a similar extent applying lower forces, if compared to the non-vibration assisted procedure. The compressive residual stress of these surfaces was also proved to increase by effect of vibration-assistance (Bozdana and Gindy, 2008). However, these studies did not include an extensive analysis of the influence of different parameters, and used a different tool from the one proposed in this paper.

The VABB process developed in this contribution was protected in Spain by Jerez-Mesa et al. (2017), and its functioning regime was confirmed experimentally by the same authors (Jerez-Mesa et al., 2018a), concluding that a stable $39,1-\mathrm{kHz}$ signal was transmitted through the material by effect of the vibration-assistance. The topological effects of the process performed by this tool were confirmed on AISI 1038 material by Jerez-Mesa et al. (2018b), concluding that the topological improvement of the surface was obtained by applying different parameters according to the original $S_{q}$ value, defining its amplitude. The authors also concluded that the selection of VABB processing parameters is contingent, and depends on the state of the original surface and the material.

This paper tackles with the surface integrity characterization of Ti6Al-4 V surfaces finished by adjacent ball-end mill passes, after being treated by an ultrasonic vibration-assisted ball burnishing operation. The results shall be analyzed in terms of surface texture, hardness and residual stress after processing. At sight of the results, different combinations of process parameters shall be proposed to execute the process according to an optimization target. These results are necessary for titanium manufacturers willing to apply the process on that material and conferring their parts with special properties, which can be mastered by the adequate application of the process. The applications are varied, and comprise parts included in the aeronautical, medical and general industrial sectors.

\section{Experimental methodology}

\subsection{Ti- 6 Al-4V alloy}

The experiments were performed on workpieces of Ti-6Al-4 V alloy (Table 1), extracted from a raw material provided as a $105 \times 95 \times 165 \mathrm{~mm}$ forged block. This is a biphasic material composed by $\alpha+\beta$ structures. The material was initially characterized by Vickers indentation tests and tensile tests, obtaining the standard properties included in Table 2 .

Table 1

Ti-6Al-4V weight composition according to AFNOR L14-601.

\begin{tabular}{lllllllll}
\hline Component & $\mathrm{Ti}$ & $\mathrm{Al}$ & $\mathrm{V}$ & $\mathrm{Fe}$ & $\mathrm{O}$ & $\mathrm{C}$ & $\mathrm{N}$ & $\mathrm{H}$ \\
\hline Weight (\%) & $88.1-91$ & $5.5-6.75$ & $3.5-4.5$ & $\leq 0.25$ & $\leq 0.2$ & $\leq 0.08$ & $\leq 0.05$ & $\leq 0.01$ \\
\hline
\end{tabular}


Table 2

Grade 23 Ti-6Al-4V properties.

\begin{tabular}{ll}
\hline Property & Value \\
\hline Young's Modulus & $110 \mathrm{GPa}$ \\
Yield strength & $870 \mathrm{MPa}$ \\
Self-hardening coefficient & 0.3 \\
HV $_{100}$ Hardness & 310 \\
\hline
\end{tabular}

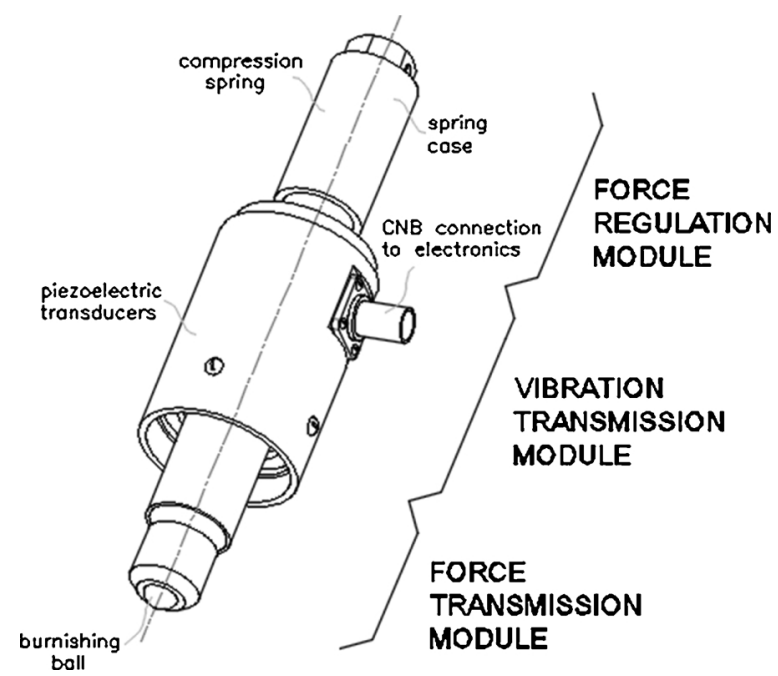

Fig. 2. Overview of the vibration-assisted ball burnishing tool.

\subsection{Vibration-assisted ball burnishing tool and equipment}

The VABB tool used in these experiments consists of three attached units, as shows Fig. 2. The preload or static force exerted on the material is regulated by means of the compression of a spring embedded in a cylinder that also serves as tool holder. The intermediate body is comprised by the case in which four stacked piezoelectric disks are installed. These elements are excited by an external circuit, inducing a variation in their thickness in phase with the alternate provided current. As the stack is joint to a sonotrode (the third and last tool component), this fluctuation is thus transmitted as a resonant wave. The sonotrode is also the part where the burnishing ball is supported, and, therefore, enables the tool to transmit both the preload force and the vibratory force to the material, succeeding in applying the VABB process. A detailed functioning pattern and characterization can be found in Jerez-Mesa et al. (2018a), where it was confirmed that the tool transmits an oscillating force characterized by a $39.1-\mathrm{kHz}$ frequency and $\pm 3.5 \mathrm{~N}$ amplitude, regardless of the preload level.

All tests were performed in a HURON KX10 3-axis milling machine equipped with a Kistler 9257B dynamometer, where the workpiece was fixed. The data measured through a Kistler 5019 A amplifier was registered using the DynoWare software, monitoring the applied forces during each test for later analysis.

\subsection{Workpiece surface preparation}

All surfaces were prepared by an initial surfacing operation with a multi-insert front milling tool followed by three different ball-end milling strategies with a TiN-coated hemispherical tool, obtained by changing the lateral offset between passes, i.e. the radial depth of cut $a_{e}$. Therefore, three different original textures were obtained (Table 3). The chosen parameters can be identified with realistic machining conditions applied in an industrial context. Defining these parameters by adopting this approach is not casual, since it is of high importance to take profit of the derived results for potential industrial applications.
Table 3

Machining parameters applied to obtain the three original surface topologies.

\begin{tabular}{lllll}
\hline \multirow{2}{*}{ Original Surface } & \multicolumn{4}{l}{ Machining parameters } \\
\cline { 2 - 5 } & $a_{e}(\mathrm{~mm})$ & $a_{p}(\mathrm{~mm})$ & Tool diameter $(\mathrm{mm})$ & $v_{c}(\mathrm{~m} / \mathrm{min})$ \\
\hline $\mathrm{S}^{\circ}{ }_{1}$ & 0.5 & 0.2 & $\emptyset 10$ & 70 \\
$\mathrm{~S}^{\circ}{ }_{2}$ & 0.8 & & & \\
$\mathrm{~S}^{\circ}$ & 1.1 & & & \\
\hline
\end{tabular}

Table 4

Factors implicated in the experimental execution. Left: Factors varied in the Taguchi array. Right: Factors at constant level throughout the tests.

\begin{tabular}{|c|c|c|c|c|c|}
\hline \multicolumn{4}{|c|}{ Factors varied in the experimental design } & \multicolumn{2}{|c|}{ Factors kept constant } \\
\hline \multirow[t]{2}{*}{ Factors } & \multicolumn{3}{|c|}{ Levels } & \multirow[t]{2}{*}{ Factor } & \multirow[t]{2}{*}{ Value } \\
\hline & 1 & 2 & 3 & & \\
\hline$F_{p}(\mathrm{~N})$ & 150 & 250 & 350 & $\begin{array}{l}\text { lateral pass } \\
\text { width }\end{array}$ & $0.3 \mathrm{~mm}$ \\
\hline$n_{p}$ & 1 & 2 & 3 & $\begin{array}{l}\text { burnishing ball } \\
\text { diameter }\end{array}$ & $10 \mathrm{~mm}$ \\
\hline $\begin{array}{c}v_{f}(\mathrm{~mm} / \\
\mathrm{min})\end{array}$ & 300 & 600 & 900 & ball material & $\begin{array}{l}60 \mathrm{Cr} 3 \text { hardened } \\
\text { chromium steel }\end{array}$ \\
\hline $\mathrm{S}^{\circ}$ & 1 & 2 & 3 & lubrication & none \\
\hline St & bn 0 & bn $90 / 0$ & nb0 & & \\
\hline
\end{tabular}

\subsection{Experimental design}

Analyzing the effect of VABB on the surface modification of the Ti6Al-4BV workpiece requires testing different parameters at different levels to attain a general vision of the overall system. To reduce the number of tests, an L27 Taguchi orthogonal array was used to develop the experimental plan, including five different factors at three levels (Table 4), along with three paired interactions among three of them.

These factors were chosen among the most influential ones in the VABB process, namely:

1 Preload force- $\boldsymbol{F}_{\boldsymbol{p}}$. Force exerted by the spring by being compressed on the surface, responding to Hooke's law. Compression length was controlled by selecting the appropriate negative $\Delta z$ coordinate in the NC routine.

2 Number of passes- $\boldsymbol{n}_{\boldsymbol{p}}$. Total successive iterations performed during the burnishing operation on a specific surface position. The higher its value, the more plastic deformation would be attained through burnishing.

3 Feed $-v_{f}$. Linear velocity at which the tool is linearly translated over the surface.

4 Original surface topology- $S^{\circ}$. The influence of the initial surface texture on the burnishing results is of high interest. These surfaces were explained at Table 3 .

5 Strategy-St. This parameter describes the trajectory followed by the burnishing ball to cover the whole target surface $n_{p}$ times. The resulting strategies have been developed by combining different burnishing directions and protocols to cover the previously burnished areas, as shows Fig. 4. First passes are in all cases performed perpendicular to the initial milling direction, hence its denomination as main burnishing direction, or direction I. The " 0 " strategies are contemplated always along that direction. Alternatively, the " $90 / 0^{\prime \prime}$ strategy is based on turning alternatively $\pm 90^{\circ}$ the burnishing direction between one pass and the next one. As for the relative order between lateral offset and number of passes, the "bn" strategies cover $n_{p}$ times the whole target patch, whereas the "nb" strategy is performed by passing $n_{p}$ times one line, and then taking the lateral pass until covering the whole target patch (Fig. 3). 

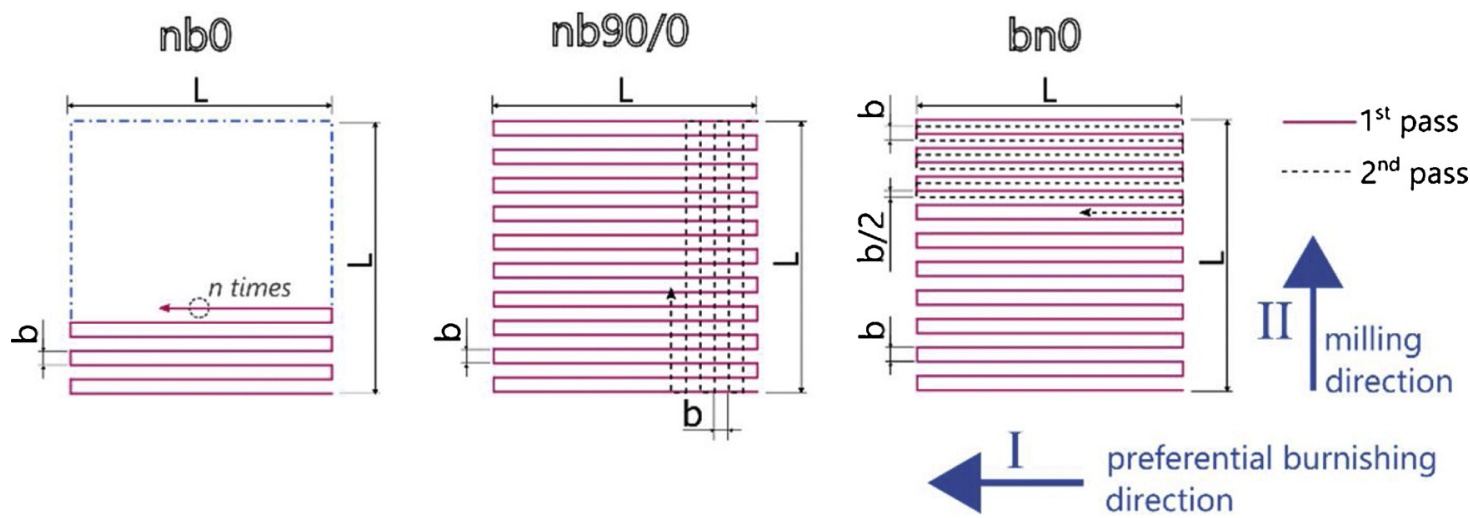

Fig. 3. Burnishing strategies included in the DOE and nomenclature of the directions referenced in the text.

Table 5

Experimental design derived from an L27 $\left(3^{13}\right)$ Taguchi orthogonal array.

\begin{tabular}{|c|c|c|c|c|c|}
\hline $\begin{array}{l}\text { Column in original array } \\
\text { Run }\end{array}$ & $\begin{array}{l}1 \\
F_{p}(\mathrm{~N})\end{array}$ & $\begin{array}{l}2 \\
n_{p}\end{array}$ & $\begin{array}{l}5 \\
v_{f}(\mathrm{~mm} / \mathrm{min})\end{array}$ & $\begin{array}{l}7 \\
S^{\circ}\end{array}$ & $\begin{array}{l}10 \\
\text { St. }\end{array}$ \\
\hline 1 & 150 & 1 & 300 & 1 & nb0 \\
\hline 2 & 150 & 1 & 600 & 2 & bn $0 / 0$ \\
\hline 3 & 150 & 1 & 900 & 3 & bn0 \\
\hline 4 & 150 & 3 & 300 & 2 & bno \\
\hline 5 & 150 & 3 & 600 & 3 & nb0 \\
\hline 6 & 150 & 3 & 900 & 1 & bn $0 / 0$ \\
\hline 7 & 150 & 5 & 300 & 3 & bn $0 / 0$ \\
\hline 8 & 150 & 5 & 600 & 1 & bn0 \\
\hline 9 & 150 & 5 & 900 & 2 & nb0 \\
\hline 10 & 250 & 1 & 300 & 3 & bn $0 / 0$ \\
\hline 11 & 250 & 1 & 600 & 1 & bn0 \\
\hline 12 & 250 & 1 & 900 & 2 & nb0 \\
\hline 13 & 250 & 3 & 300 & 1 & nb0 \\
\hline 14 & 250 & 3 & 600 & 2 & bn $0 / 0$ \\
\hline 15 & 250 & 3 & 900 & 3 & bno \\
\hline 16 & 250 & 5 & 300 & 2 & bn0 \\
\hline 17 & 250 & 5 & 600 & 3 & nb0 \\
\hline 18 & 250 & 5 & 900 & 1 & $\mathrm{bn} 0 / 0$ \\
\hline 19 & 350 & 1 & 300 & 2 & bn0 \\
\hline 20 & 350 & 1 & 600 & 3 & nb0 \\
\hline 21 & 350 & 1 & 900 & 1 & $\mathrm{bn} 0 / 0$ \\
\hline 22 & 350 & 3 & 300 & 3 & bn $0 / 0$ \\
\hline 23 & 350 & 3 & 600 & 1 & bn0 \\
\hline 24 & 350 & 3 & 900 & 2 & nb0 \\
\hline 25 & 350 & 5 & 300 & 1 & nb0 \\
\hline 26 & 350 & 5 & 600 & 2 & bn $0 / 0$ \\
\hline 27 & 350 & 5 & 900 & 3 & bn0 \\
\hline
\end{tabular}

As a consequence of the experimental design, the final L27 Taguchi orthogonal array is represented in Table 5 . The 27 runs were executed on the workpiece twice, as represented in Fig. 4. The first set of experiments were executed by applying the vibration-assisted process, whereas the second set was developed executing the conventional one, so that the results could be mutually compared to assess the effects of the assistance of vibrations.

\subsection{Methods applied for result analysis}

The described burnishing patches were studied by measuring different features of their surface integrity, namely: texture, residual hardening and residual stress state. The following subsections explain the descriptors that were chosen to characterize the change of surface integrity, along with the techniques used to measure and calculate them.

\subsubsection{Topological data characterization}

The evaluation of the topological state of a surface using two-dimensional parameters has been used by many researchers, as presented in the introduction of this paper. However, considering that the effect of VABB is highly anisotropic, as deduced by Jerez-Mesa et al. (2018b), the total adequacy of 2D parameters to wholly describe the final surface can be questioned. Alternatively, the same authors proposed a set of four 3D parameters defined at the ISO 25178 standard that wholly describe the effects of VABB on the surface, as they successfully account for the scale reduction of the texture features and the redistribution of the material on the surface. This is the parameter set chosen to characterize the effects of VABB in these works (Table 6).

The referred parameters were calculated on datasets acquired by an ALICONA Infinite Focus device from all VABB and NVABB patches, thus registering their topologies by successive image acquisition along the vertical direction, without contact with the surface. The 10x objective was used to perform this acquisition, delivering to the system a $100 \mathrm{~nm}$ vertical resolution.

\subsubsection{Residual stress measurement}

The X-ray diffraction method was applied to evaluate the superficial residual stress after VABB. The technique is based on applying Bragg's law while quantifying the change of interplanar spacing inside crystals which conserve elastic strain confined inside plastically deformed crystals due to VABB. Albeit the major drawback of this diffraction method is the low depth to which compressive residual stresses measurements are assessed, its technical availability and feasibility makes it proper to evaluate VABB results in this experimental plan. The experimental application was performed with a V- $\alpha$ anode, $360 \mathrm{~s}$ of exposition time, and 13 measures. The post-processing method was curve fitting s vs $\sin ^{2}(\Psi)$. More information about the method can be found at Prevey (1986).

The outcome of the application of the method on all VABB tests was delivered in terms of the residual stress tensor (Eq. 1)

$\sigma=\left(\begin{array}{cc}\sigma_{I} & \tau_{12} \\ \tau_{21} & \sigma_{I I}\end{array}\right)$

where $\sigma_{I}$ is the normal stress along direction I, $\sigma_{I I}$ is the normal stress along direction II, and $\tau_{12}$ and $\tau_{21}$ are the shear stress associated to the tensor.

The analysis of this tensor's components shall be included in the discussion the directional effects of the VABB process. A second indicator that shall be included in the analysis is the von Mises stress, $\sigma_{v m}$, calculated as a descriptor of the general residual stress state of the surface through Eq. 2, and constructed as described by Han and Reddy, (2012) for general flat stress tensors.

$\sigma_{v m}=\sqrt{\sigma_{I}^{2}+\sigma_{I}^{2}-\sigma_{I} \sigma_{I I}+3 \tau_{21} \tau_{12}}$

\subsubsection{Metallurgical characterization of subsurface layers}

Changes in metallography are usually evidenced through a change of the hardness magnitude, as the phases that compose a certain metal 

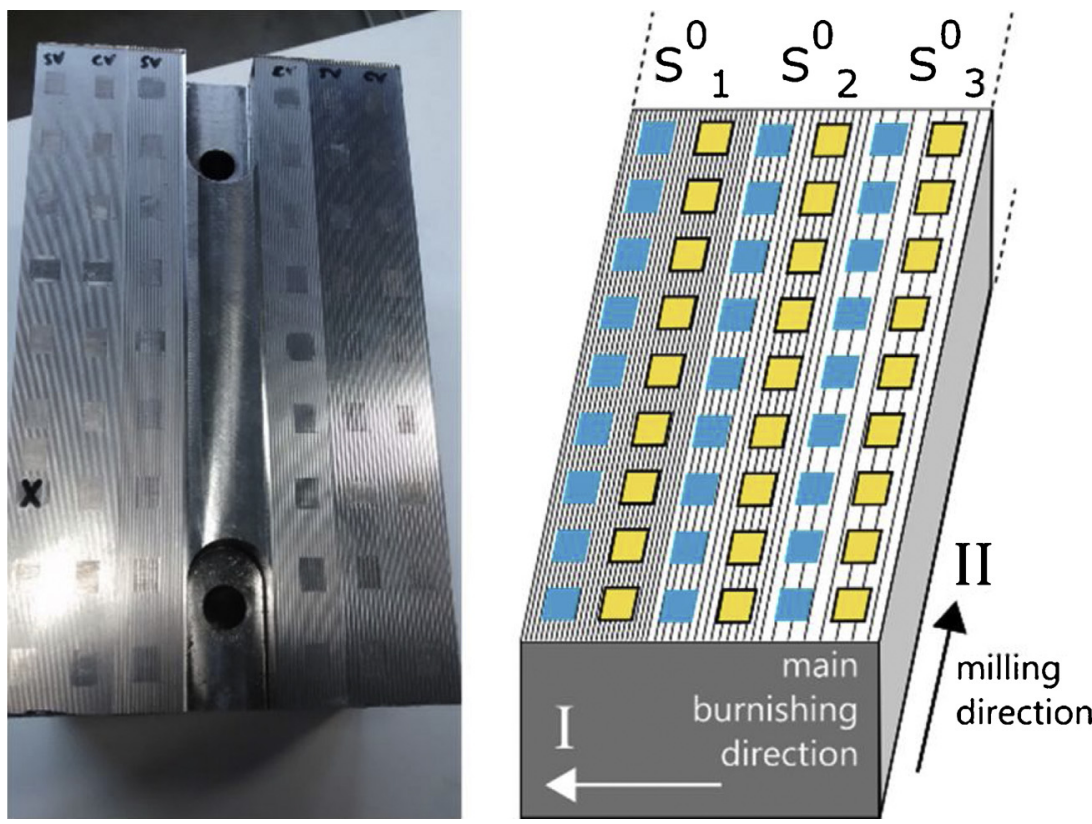

Fig. 4. Right. Schematic representation of the VABB (non-contoured yellow patches) and NVABB (contoured blue patches) tests performed on the Ti-6Al-4V surfaces. Left. Real workpiece. (For interpretation of the references to colour in this figure legend, the reader is referred to the web version of this article.)

have different structures, and consequently pose different behaviors towards indentation tests. For that reason, in addition to visual inspection with a SEM of the microstructure of the Ti-6Al-4 V subsurface layers, Vickers hardness tests with a Buehler 5114 hardness testing machine were performed to evaluate the deep change of hardness of the specimens after VABB and its non-assisted complementary process. The calculation of the Vickers hardness was undertaken according to the ASTM E384 Standard (American Society for Testing and Materials, 2017). Indentations were performed at different depths of the surface distanced by $50 \mu \mathrm{m}$. For each deep level, 20 indentations were made and measured and averaged, and an error term was calculated as an addition of two terms, namely: the statistical uncertainty, $E_{s}$, associated to the averaging calculation, and an experimental error, $E_{\text {exp }}$, introduced by the limitation in optical resolution given by the microscope.

\section{Experimental results and discussion}

\subsection{Burnishing force monitoring}

As the sampling frequency of the Kistler amplifier is $2 \mathrm{kHz}$, the registered force signals did not evidence the vibratory component delivered by the piezoelectric. Under this circumstance, the forces acquired during the $\mathrm{VABB}$ and the NVABB tests correspond to the quasi-static force excerpted on the material. Fig. 5 shows, as an example, the evolution of the burnishing force for test \#25 in the NVABB and VABB process, evidencing a stable value during the process. All the signals were processed through a Matlab routine, and the mean, maximum and minimum values were calculated (Fig. 5). It can be concluded that the actual applied forces during the tests agree in average with the values expected from the Taguchi array, whereas a uniform, and therefore acceptable, variation is detected.

\subsection{Topological parameters}

\subsubsection{Original surfaces}

The surfaces machined on the Ti- $6 \mathrm{Al}-4 \mathrm{~V}$ workpiece present the three-dimensional parameters represented in Fig. 6. As could be predicted, the $S_{q}$ value is lower as the offset between machining passes decreases, evidencing a lower scale of the surface features. However, the skewness and kurtosis values show that, in all surfaces, the material is distributed according to a quasi-Gaussian distribution. In all cases, the distribution could be considered as equivalent, meaning that by changing the offset, similar distributions are obtained. Consequently, it can be stated that by reducing the offset between ball-end milling passes, similar surfaces can be obtained at different scales. This effect is easily observed in Fig. 6 by checking the three-dimensional representation of the reconstructed acquired surface.

The following subsections include the VABB effects on the considered $\mathrm{S}$ parameters.

\subsubsection{Sq parameter: scale reduction}

Firstly, a statistical ANOVA considering $S_{q}$ as response variable reveals that the original topology is the most important factor on its variation (Fig. 7). In fact, its effect is so remarkable, that the sources of variation due to the rest of the factors are hidden by it. Alternatively, the p-values associated to the statistical tests were consulted, revealing that only the preload is an influential effect on the response, if a $5 \%$ significance level is considered. Consequently, applying only one pass should be enough to achieve sufficient surface reduction, whereas the

Table 6

Parameters selected to describe the topological effects of VABB.

\begin{tabular}{|c|c|c|}
\hline Type & Factor & Interpretation \\
\hline \multirow[t]{3}{*}{ Amplitude } & $S_{q}$ & The mean square root height describes the general scale of the surface. \\
\hline & $S_{s k}$ & Skewness describes the relative weight of peaks vs valleys on the surface $\left(S_{s k}>0\right.$ indicates more valleys than peaks) \\
\hline & $S_{k u}$ & $\begin{array}{l}\text { Kurtosis refers to the abruptness of the surface. The Gaussian value of } 3 \text { is usually taken as a reference, so that } S_{k u}>3 \text { describes abrupt surfaces, and } S_{k u}< \\
3 \text { is associated to low slope surfaces or surfaces represented by bimodal distributions. }\end{array}$ \\
\hline Hybrid & $S_{t d}$ & Main texture direction of the surface features, in degrees. \\
\hline
\end{tabular}



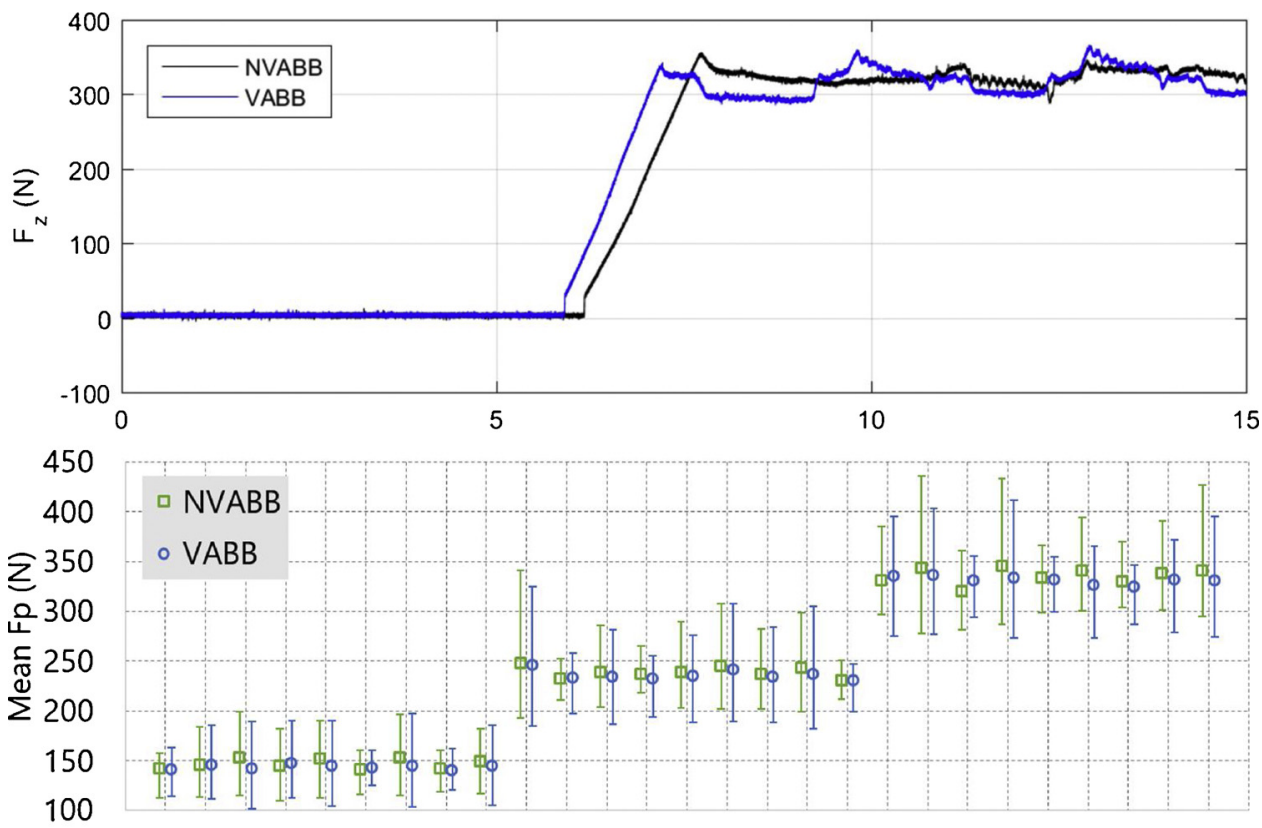

$123 \quad 4 \quad 5 \quad 6 \quad 7 \quad 8 \quad 9101112131415161718192021222324252627$

\#run

Fig. 5. Top. Registered preload during test \#25 in the VABB and NVABB cases. Bottom. Mean, maximum and minimum preload registered for each NVABB and VABB test.

feed and the strategy are indifferent. No interactions are detected in this case.

Derived from this analysis, results were graphically rearranged by grouping tests according to the original surface on which they were performed. Fig. 8 shows that the continuous decrease of the $S_{q}$ general amplitude parameter can be observed in all surfaces as the preload increases. As that decrease is monotonous, no threshold value revealing a maximum improvement of the surface is achieved in any of the three textures, revealing that further improvement could still be attained by a higher degree of plastification.

\subsubsection{Ssk and Sku parameters: height redistribution}

The evolution of skewness and kurtosis amplitude descriptors as more plastic strain is performed evidences the change in the height distribution (Fig. 8). In all cases, the application of VABB rectifies the skewness of the original surfaces, by reducing it towards zero. Therefore, VABB balances the amount of valleys regardless of the degree of plastic deformation. However, the evolution of the kurtosis factor changes depending on the surface which is target of analysis. Whereas it is not sensitive to the increase of plastic strain for surfaces $S_{2}^{\circ}$ and $S_{3}^{\circ}$, it actually increases to Gaussian values in surface $S_{1}^{\circ}$. Consequently, the VABB process does not change essentially the height distribution if the original surface has too abrupt original features.

The explained effect can be easily identified also in the height histogram representation of each surface. Fig. 9 depicts a sequential representation of height histograms of singular tests for all three original

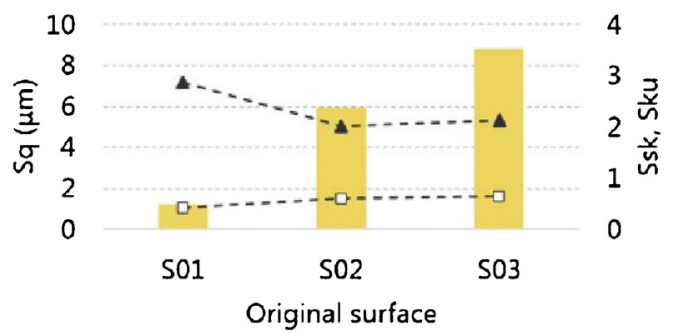

Sq $-\square=\cdot$ Skk - - Sku

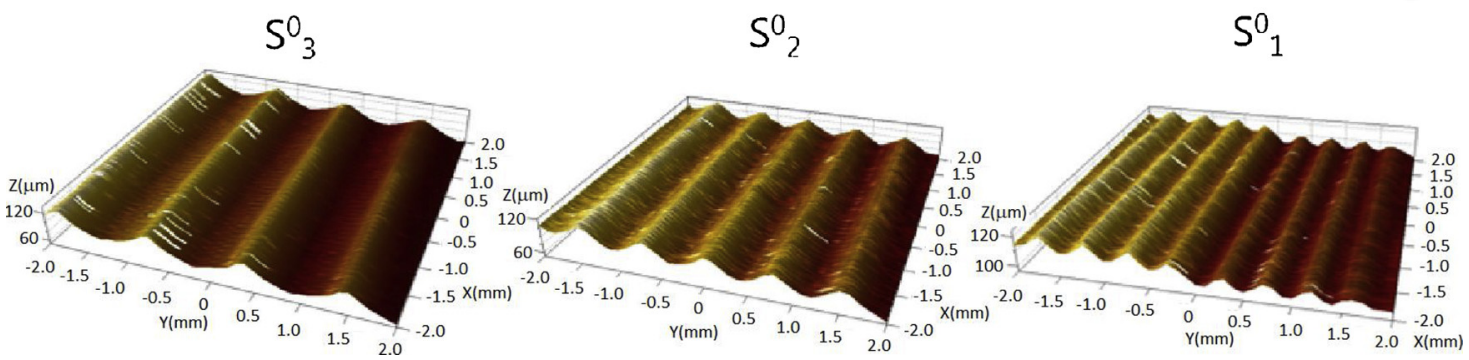

Fig. 6. Top. $\mathrm{S}$ parameters describing the original surfaces of Ti-6Al-4 V. Bottom. 3D reconstruction of the original topologies. 


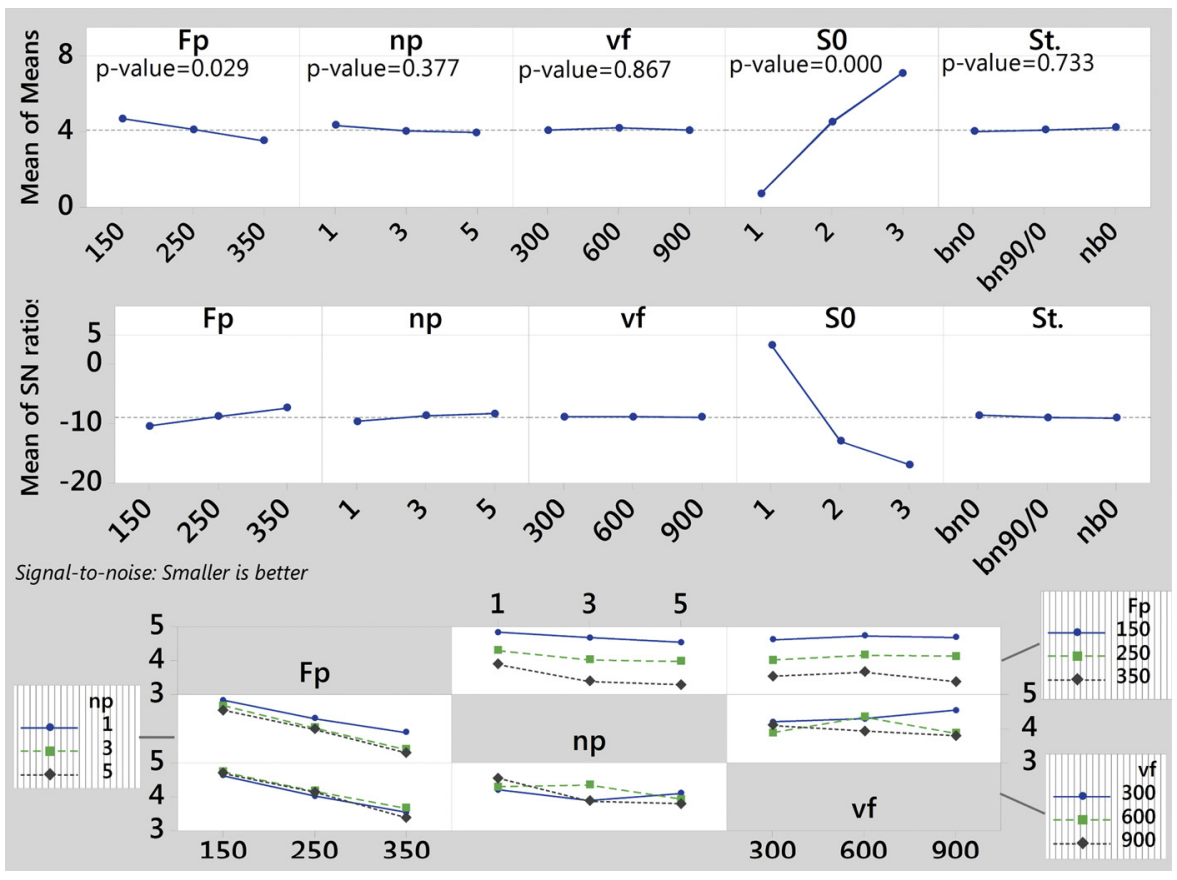

Fig. 7. VABB mean effects, $\mathrm{S} / \mathrm{N}$ ratios and interaction plots. ANOVA response variable: $\mathrm{S}_{\mathrm{q}}$.

surfaces. Only is in $S^{\circ}{ }_{1}$ the effect of VABB conspicuous, in terms of bimodality neutralization and surface scale reduction, as test \#21 presents a Gaussian height distribution with lower extreme points. Much on the contrary, bimodality cannot be erased from surface $\mathrm{S}_{3}^{\circ}$, what was observed in the fact that the kurtosis value is kept constant. Consequently, for this kind of surface, the VABB process proves to reduce the scale of its texture, as revealed the analysis of the $S_{q}$ factor, but it is not able to change the height distribution. This behavior is similar for the $\mathrm{S}^{\circ}$ surface. Consequently, the original scale of the surface features defines the effectiveness of the VABB process to modify comprehensively the target surface.

\subsubsection{Std: texture direction}

All values of the $S_{t d}$ parameter are kept at $90^{\circ}$ after VABB process. This fact evidences that, in this case, VABB cannot change the direction of the material surface. Fig. 10 shows in a height colormap the surface after test \#21, evidencing that the original machining marks are not erased, even in this case where an accused reduction of $S_{q}$ was measured.

\subsubsection{Evaluation of vibration assistance}

The direct comparison of the $S_{q}$ parameter of all VABB and NVABB tests performed on the Ti-6Al-4V workpiece leads to interesting results. Whereas $\mathrm{S}_{2}^{\circ}$ and $\mathrm{S}_{3}^{\circ}$ evidence similar results when the vibration-assistance is introduced, the effectiveness of the VABB process seems to be more effective on the $S_{1}^{\circ}$ surface (Fig. 11). Although the advantage of using VABB with regards to NVABB is modest, vibration assistance still shows more positive effect the lower the $S_{q}$ parameter characterizing the target surface. The evidence shows therefore, that the effect of VABB seems to have an inverse correlation with the gradient of $S_{q}$ : as it is reduced, the effect of VABB is increasingly positive. This statement was also true for AISI 1038 surfaces, at sight of the results obtained by Jerez-Mesa et al. (2018b), and reinforces the incidence that the original texture has on the ball burnishing results, as well as the effectiveness of

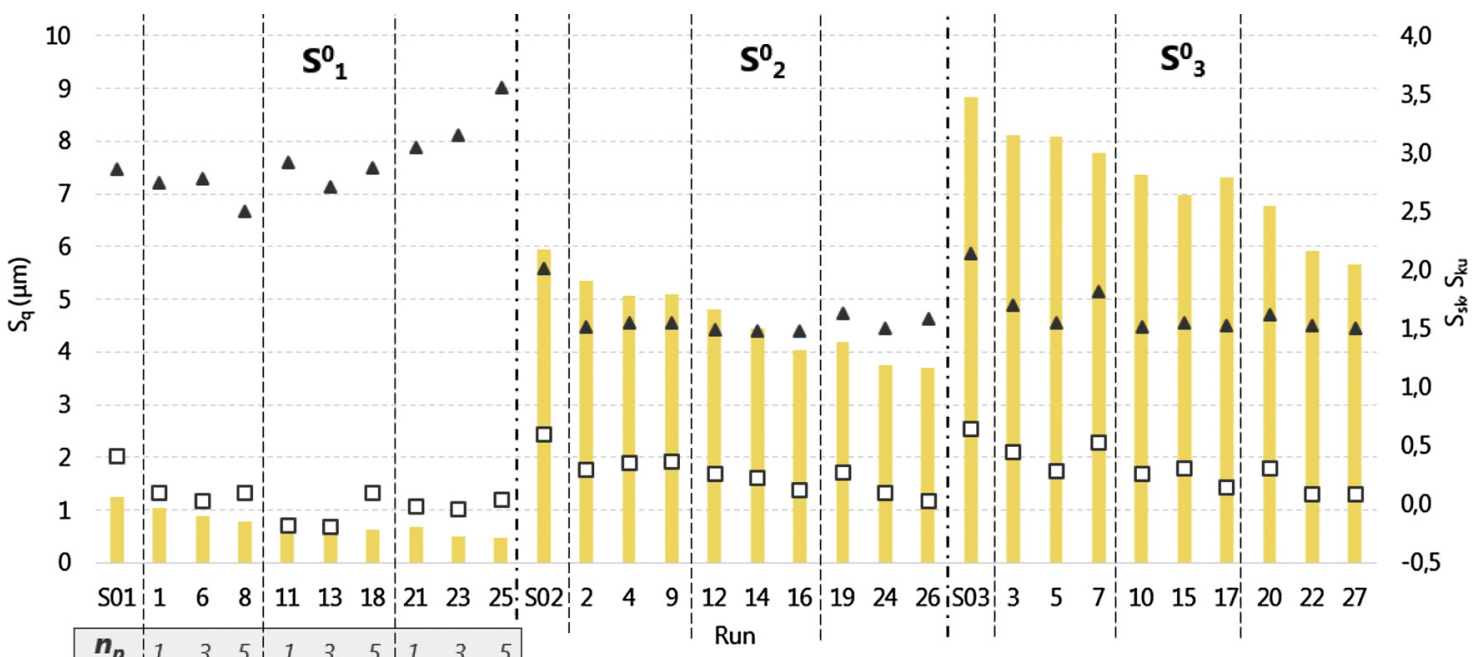

Sq $\square$ Ssk $\triangle$ Sku

Fig. 8. S parameter evolution on all VABB tests. 

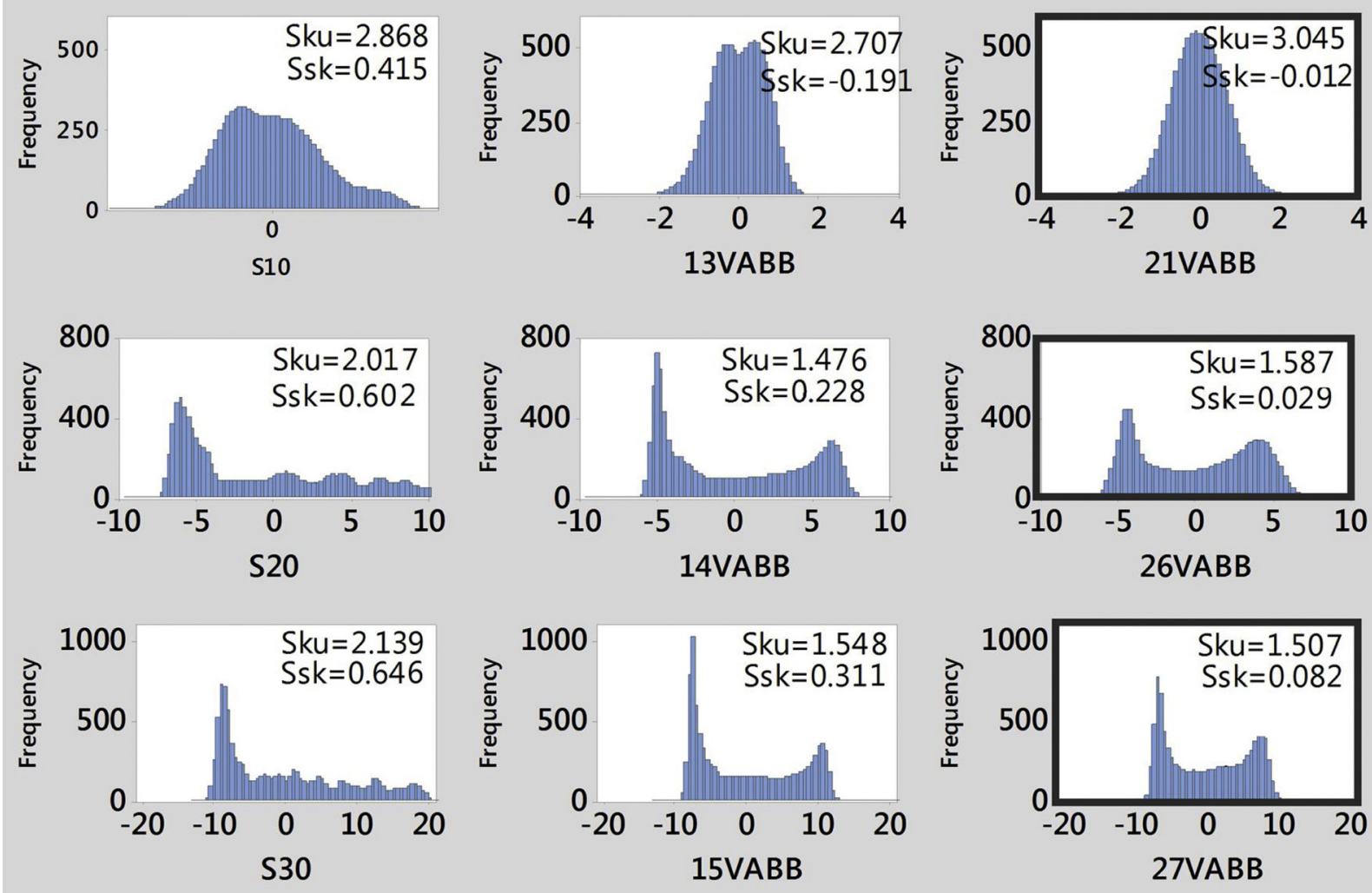

Fig. 9. Height histograms represented for all original surfaces (left), intermediate tests (center) and tests with highest preload and number of passes (right).

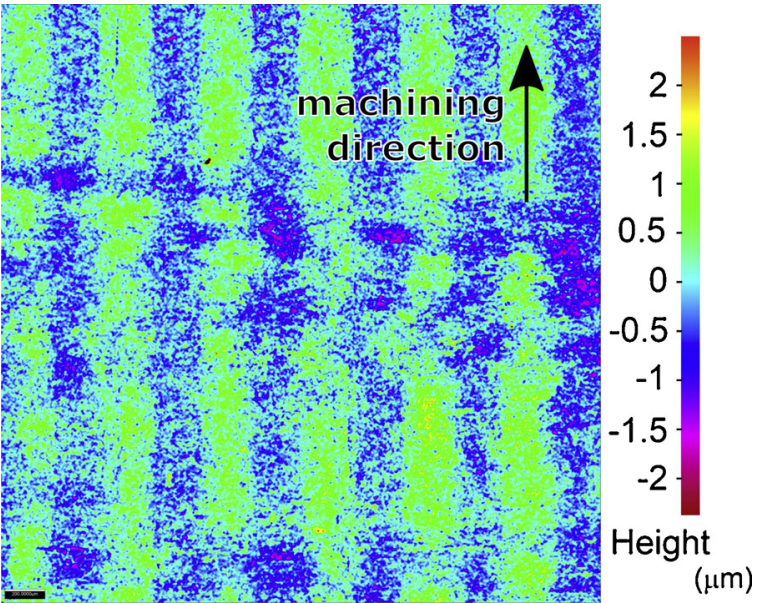

Fig. 10. Height color map of test \#21 VABB. the vibration-assistance.

\subsubsection{Recommended process parameters according to texture results}

The previous results have evidenced that it is possible to improve the surface texture of Ti-6Al- $4 \mathrm{~V}$ ball-end milled surfaces by applying the correct ball burnishing parameters. The achievement of textures with minimum $S_{q}$ and $S_{s k}$ and $S_{k u}$ Gaussian values was defined as the optimization target. Textures characterized by these parameters are expected to be the most balanced in terms of wear reduction and lubrication retention, regarding future applications of ball burnishing on engineering surfaces. Based on this premise, only the preload and the type of process proved to be influential, whereas results were independent from the strategy, the number of passes, and the feed. However, from the point of view of productivity, 1 pass and $900 \mathrm{~mm} /$ min should be recommended to achieve surface improvement with minimum processing time. As a summary, Table 7 shows the recommended parameters to treat end-milled surfaces.

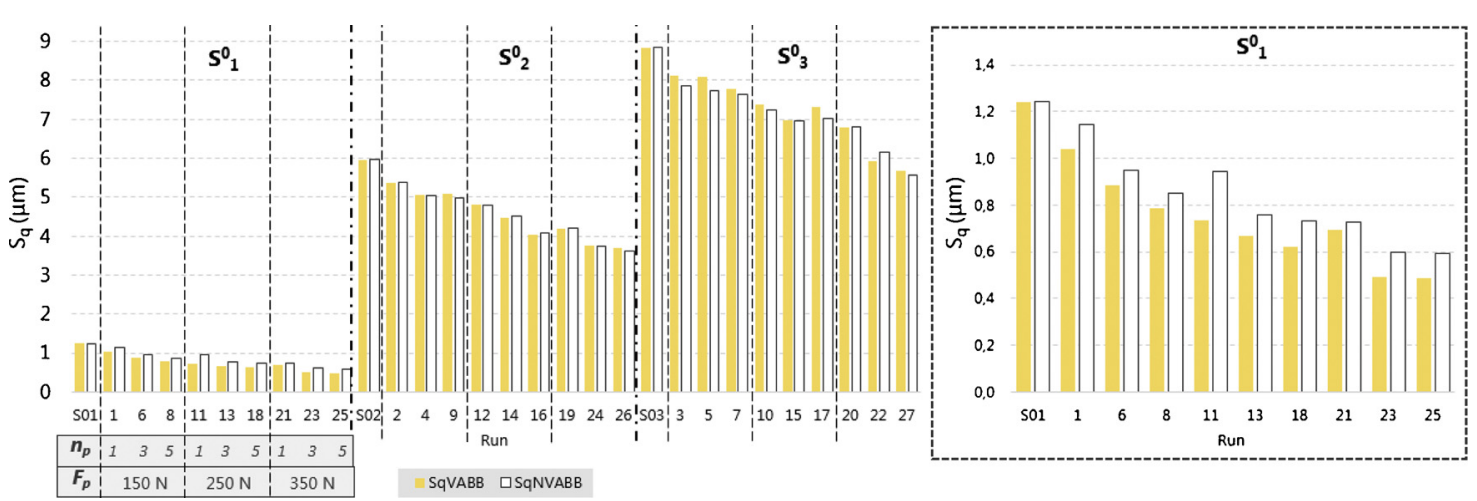

Fig. 11. Left. Direct comparison of the $S_{\mathrm{q}}$ parameter of VABB and NVABB tests on Ti-Al-4 V. Right. Detail of $\mathrm{S}^{\circ}{ }_{1}$ results. 
Table 7

Best parameters to treat Ti-6Al-4 V surfaces in terms of texture.

\begin{tabular}{lllll}
\hline Original texture & Process & $\mathrm{F}_{\mathrm{p}}(\mathrm{N})$ & $\mathrm{n}_{\mathrm{p}}$ & $\mathrm{v}_{\mathrm{f}}(\mathrm{mm} / \mathrm{min})$ \\
\hline $\mathrm{S}^{\circ}{ }_{1}$ & VABB & 350 & 1 & 900 \\
$\mathrm{~S}^{\circ}{ }_{2}$ & VABB/NVABB & 350 & 1 & 900 \\
$\mathrm{~S}^{\circ}{ }_{3}$ & VABB/NVABB & 350 & 1 & 900
\end{tabular}

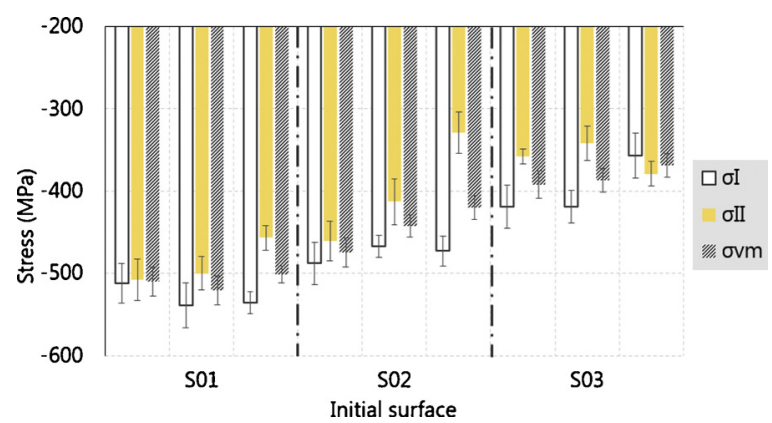

Fig. 12. Residual stress descriptors at all original surfaces.

\subsection{Mechanical parameter: residual stress}

\subsubsection{Original surfaces}

Firstly, residual stress was measured on all original surfaces three times through X-ray diffraction. Fig. 12 confirms the result repeatability by applying the method in different areas of the original surfaces. All surfaces have initially compressive residual stress, being higher as the offset between passes is reduced. Furthermore, all residual stress values are characterized by anisotropy caused by the machining operation, being $\sigma_{I}>\sigma_{I I}$. This means that, from the original machining process, the direction perpendicular to the feed movement is favored by the process. In addition,

\subsubsection{ANOVA analysis of residual stress tensor components}

The mean effects of VABB on residual stress results can be analyzed by considering the mean effects of the factors and interactions included in the model, calculated through ANOVA. The ideal parameter sets deduced from this analysis shall be then compared to experimental results. The mean effect graphs are represented in Fig. 13. Both the VABB and NVABB processes seem to deliver comparable mean effects. Secondly, the overall residual stress state, represented by $\sigma_{v m}$, is only influenced by the $F_{p}-n_{p}$ pair, meaning that it is basically dependent on the degree of plastic deformation, not the strategy applied to cover the whole surface or the velocity. Specifically, 350N-5passes are the best conditions to be applied in both VABB and NVABB if the compressive residual stress is to be maximized.

As for $\sigma_{I}$ and $\sigma_{I I}$, the strategy proves here to be an effective driver through which a desired surface direction can be reinforced, being bn90/0 the strategy favoring the former, and nb0 the latter. This result is of high importance, bearing into account that compressive residual stress prevent crack growth in fatigue regimes, so that ball burnishing can be positive in this sense if the main load direction in service is identified before applying the process, and the proper direction of burnishing is selected to perform the operation.

The mean effects of the original surface on the results is also inverted from $\sigma_{I}$ and $\sigma_{I I}$. The interpretation must be related to the original surface state. After burnishing, the relationship $\sigma_{I}>\sigma_{I I}$ is maintained in average as in the machined surfaces. However, $S^{\circ}{ }_{1}$ being more residually compressed than $S_{3}^{\circ}$ is only maintained in $\sigma_{I I}$ after VABB and NVABB whereas it is inverted in $\sigma_{I}$. The only reason why this happens is because $S_{3}^{\circ}$ is more positively affected by VABB and NVABB, and its $\sigma_{I}$ (main burnishing direction) is increased to a higher extent.

In mean terms, the combination $350 \mathrm{~N}-5$ passes is the best to maximize $\sigma_{I I}$. On the contrary, $\sigma_{I}$ reflects better results by the application of 90 or $180 \mathrm{~N}$ with 5 passes. As $\sigma_{I}$ is initially higher, this observation could reveal that stress relaxation along direction I could be associated to both NVABB and VABB if the preload is increased to a too high extent.

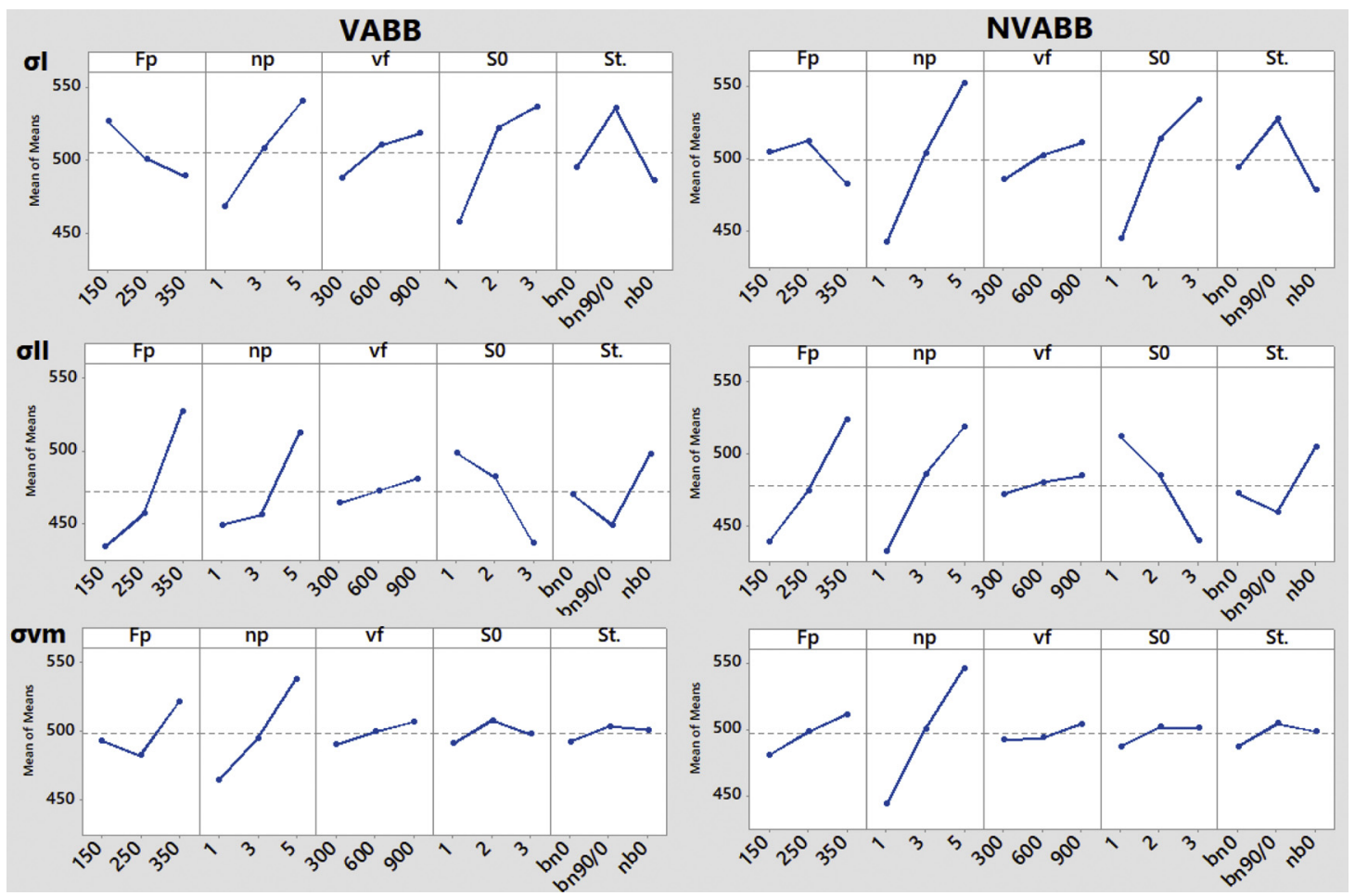

Fig. 13. VABB and NVABB mean effects. ANOVA response variable: residual stress components. 
Table 8

Best parameters to treat Ti-6Al-4 V surfaces in terms of residual stress.

\begin{tabular}{|c|c|c|c|c|c|c|c|c|}
\hline Original texture & Process & $F_{p}(\mathrm{~N})$ & $n_{p}$ & $v_{f}(\mathrm{~mm} / \mathrm{min})$ & Strategy & Maximizes & Real test & Residual stress increase \\
\hline $\mathrm{S}_{1}^{\circ}$ & VABB or NVABB & 350 & 5 & 900 & nbo (along II) & $\begin{array}{l}\sigma_{I I} \\
\sigma_{v m}\end{array}$ & \#25 & $\Delta \sigma_{I I}=21.0 \%$ \\
\hline $\mathrm{S}_{2}^{\circ}$ & VABB or NVABB & 350 & 5 & 900 & nbo (along II) & $\begin{array}{l}\sigma_{I I} \\
\sigma_{v m}\end{array}$ & \#26 & $\Delta \sigma_{I I}=39.1 \%$ \\
\hline $\mathrm{S}_{2}^{\circ}$ & VABB or NVABB & 350 & 5 & 900 & $n b 0$ & $\begin{array}{l}\sigma_{I I} \\
\sigma_{v m}\end{array}$ & \#27 & $\Delta \sigma_{I I}=81.0 \%$ \\
\hline
\end{tabular}

Table 9

Tested conditions for hardness tests, on $\mathrm{S}_{1}^{\circ}$ surfaces.

\begin{tabular}{lll}
\hline Process & Strategy & Fixed parameters \\
\hline VABB & nb0 & $F_{p}=350 \mathrm{~N} ; n_{p}=5 ; v_{f}=900 \mathrm{~mm} / \mathrm{min}$ \\
NVABB & bn90/0 & \\
\hline
\end{tabular}

3.3.3. Recommended process parameters according to residual stress results

The residual stress results have shown that there is not a single combination of parameters able to improve all directions simultaneously. However, common trends have been identified. 5 passes and $350 \mathrm{~N}$ should be in general applied, whereas the velocity is not an influential parameter. The strategy should be adequately selected to maximize the desired direction of the workpiece, according to the expected main direction of cyclic loads, to prevent crack growth originated by those. Checking on the actual tests performed on the workpieces, allowing to confirm these observations, Table 9 shows sets of parameters that have shown good results according to the described guidelines. These results agree with the topological results described above, except for the fact that 5 passes should be applied to maximize residual stress, with no negative impact on texture results (Table 8).

\subsection{Metallurgical parameter: hardness and metallography}

The previous section has shown that, although not all aspects of surface integrity can be simultaneously improved, a certain optimal set can be established to find a balanced solution for all of them. In this section, a third aspect of surface integrity is tackled to complete the assessment of the impact of VABB. To perform the study, not all Taguchi combinations have been executed. On the contrary, the preload, number of passes, and feed have been fixed (Table 9). Two different strategies have been considered, and both the NVABB and VABB were performed in a testpiece machined according to the $S^{\circ}{ }_{1}$ texture.

Four different patches were therefore performed, and were cut along the two directions of the space, generating eight different specimens, on which several Vickers microindentation tests were performed in progressively deeper layers, separated $50 \mu \mathrm{m}$ and $100 \mu \mathrm{m}$, until a
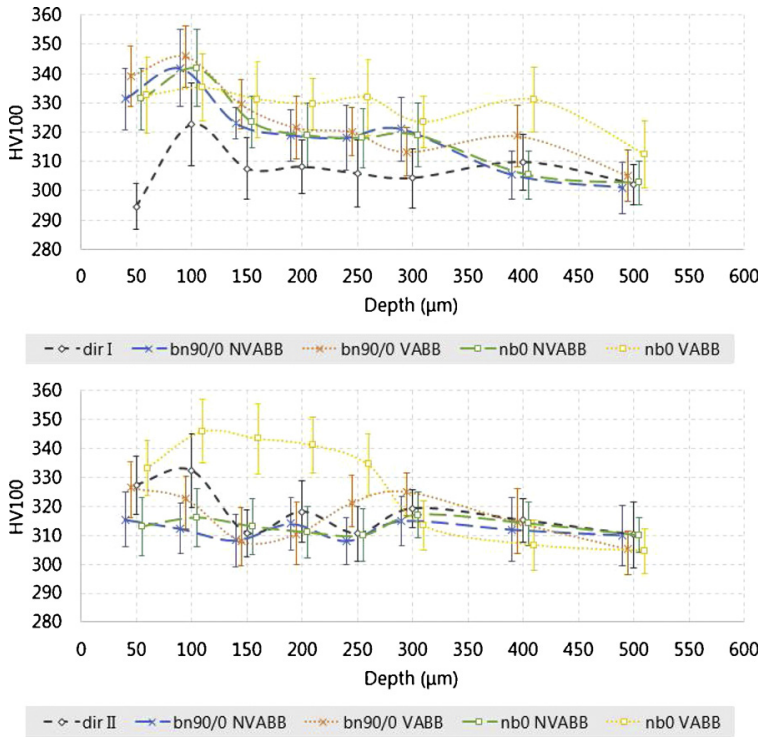

Fig. 15. Deep hardness profiles of VABB and NVABB tests. Top. Direction I. Bottom. Direction II.

$600-\mu \mathrm{m}$ depth, as shows Fig. 14. For each level, the resulting hardness values were averaged and an associated error was calculated

Fig. 15 shows the resulting deep hardness profiles of the explored surfaces. In this case, the machining process has a hardening effect on the workpiece that spans to a $100-\mu \mathrm{m}$ depth. Furthermore, the ball burnishing process seems to cause residual deep hardening, hence surface integrity improvement. In both directions, hardness profiles are substantially similar among them, regardless of the applied strategy or the type of process, except for one case. The combination of nb0 strategy and the VABB process is in overall positive along both directions. It can be stated that applying five passes of the VABB process along the same direction continuously allows to achieve a residual hardening from around 100 to $500 \mu \mathrm{m}$ deep layers.

SEM observations of the Ti-6Al-4 V surface and sub-surface layers

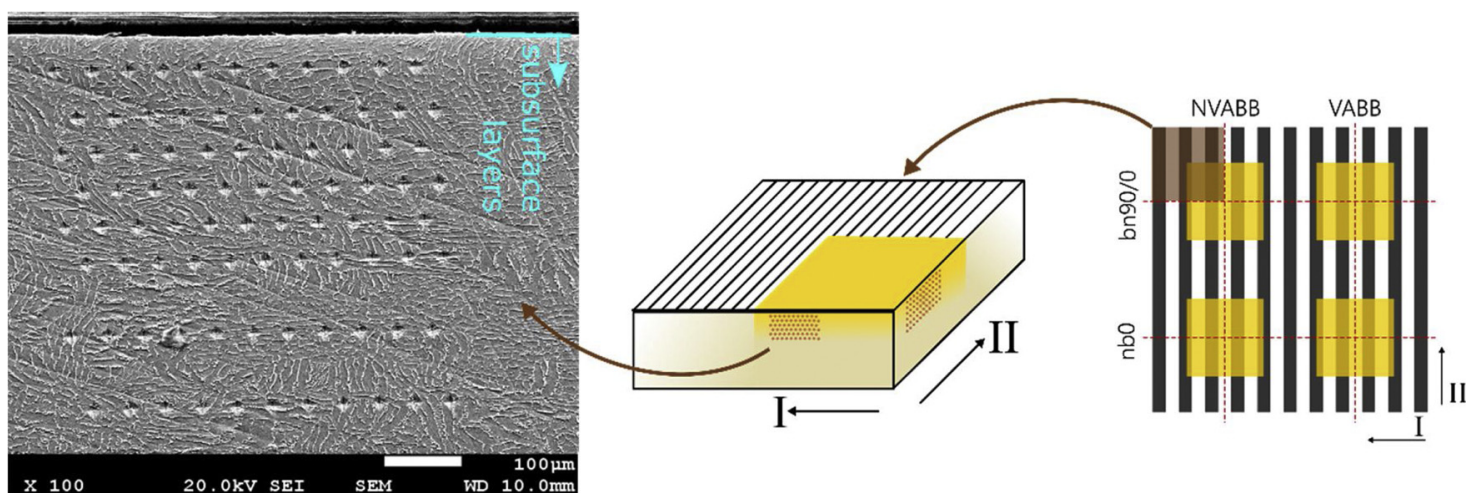

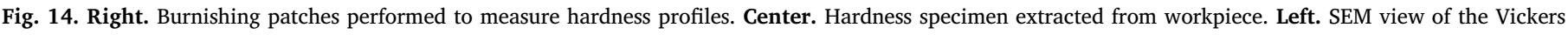
microindentation matrix performed on the subsurface layers. 


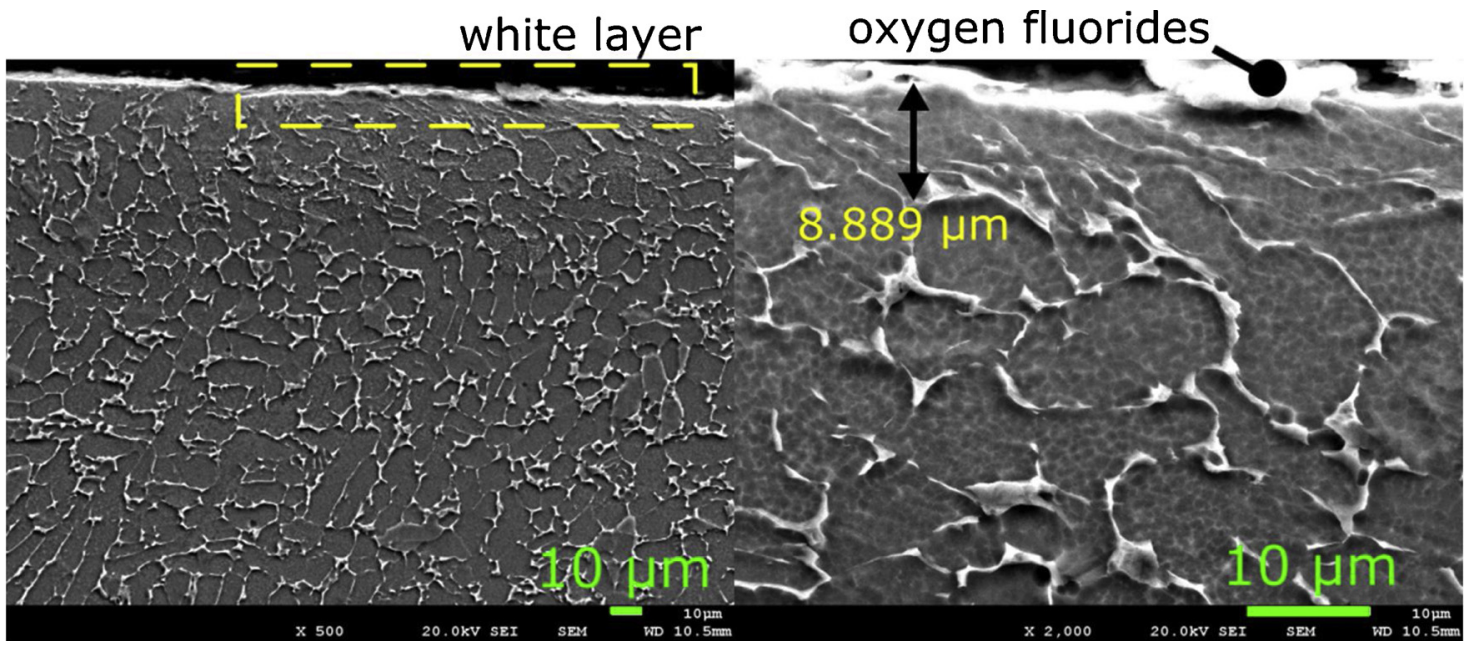

Fig. 16. $x 500$ (left) and $x 2000$ (right) SEM observations of VABB surface applying the nb0 strategy.

reveals that the effect of ball burnishing can be distinguished by the orientation of the $\alpha$ phase along the burnishing direction, by effect of the plastic deformation (Fig. 16). No further effects are present.

\section{Conclusions}

The experimental results have proved to deliver valuable information about the impact of vibration-assistance on the ball burnishing process on Ti-6Al-4 V surfaces. The conclusions can be stated as follows:

- The combination of $350 \mathrm{~N}, 5$ passes and $900 \mathrm{~mm} / \mathrm{min}$ has been found as the best processing parameter set to obtain enhanced surface features after ball burnishing on Ti-6Al-4 V surfaces.

- Vibration-assistance must be recommended to enhance ball burnishing results, as it has proved to be advantageous in terms of residual hardness and topology. However, these positive results are subjected to the $S_{q}$ descriptor being lower than $1 \mu \mathrm{m}$. That is, the extent to which vibration assistance is positive is dependent on the general scale of the original surface, agreeing with the results obtained by Jerez-Mesa et al. (2018b) on AISI 1028 surfaces.

- Vibration assistance is not influential in terms of residual stress, as results are essentially the same. In this sense, the most important factor is selecting the burnishing strategy according to the direction that wants to be reinforced.

\section{Acknowledgements}

This study was supported by the Spanish Ministry of Economy and Competitiveness [grant number DPI2015-69803-R], which is greatly appreciated.

\section{References}

Altenberger, I., Nalla, R.K., Sano, Y., Wagner, L., Ritchie, R.O., 2012. On the effect of deep rolling and laser peening on the stress-controlled low and high-cycle fatigue behavior of Ti-6Al-4V at elevated temperatures up to 550XC. Int. J. Fatigue 44, 292-302.

American Society for Testing and Materials, 2017. Standard Test Methods for Vickers Hardness and Knoop Hardness of Metallic Materials. Standard No. E92-07.

Blaha, F., Langenecker, B., 1955. Dehnung von Zink-Kristallen unter Ultraschalleinwirkung. Naturwissenschaften 42 (20) 556-556.

Bozdana, A.T., Gindy, N.N., 2008. Comparative experimental study on effects of conventional and ultrasonic deep cold rolling processes on Ti-6Al-4V. Mater. Sci.
Technol. 24 (11), 1378-1384.

Bozdana, A.T., Gindy, N.N., Li, H., 2005. Deep cold rolling with ultrasonic vibrations-a new mechanical surface enhancement technique. Int. J. Mach. Tool. Manu. 45 (6), $713-718$.

Chomienne, V., Valiorgue, F., Rech, J., Verdu, C., 2016. Influence of ball burnishing on residual stress profile of a 15-5PH stainless steel. CIRP J. Manuf. Sci. Technol. 13, 90-96.

Gomez-Gras, G., Travieso-Rodriguez, J.A., Gonzalez-Rojas, H.A., Nápoles-Alberro, A., Carrillo, F.J., Dessein, G., 2015. Study of a ball burnishing vibration-assisted process. Proc. Inst. Mech. Eng. B: J. Eng. 229 (1), 172-177.

Han, W., Reddy, B.D., 2012. Plasticity: Mathematical Theory and Numerical Analysis, vol. 9 Springer Science \& Business Media, New York.

Huang, H., Pequegnat, A., Chang, B.H., Mayer, M., Du, D., Zhou, Y., 2009. Influence of superimposed ultrasound on deformability of Cu. J. Appl. Phys. 106 (11) 113514.

Huuki, J., Laakso, S.V., 2013. Integrity of surfaces finished with ultrasonic burnishing. Proc. Inst. Mech. Eng. B: J. Eng. 227 (1), 45-53.

Jerez-Mesa, R., Gomez-Gras, G., Travieso-Rodríguez, J.A., Lluma-Fuentes, J., 2017. Herramienta de bruñido con bola asistida por vibraciones ultrasónicas. Spanish patent number ES2615002. Spanish Gazette of Patents and Trademarks. Published the 01/06/2017.

Jerez-Mesa, R., Travieso-Rodriguez, J.A., Gomez-Gras, G., Lluma-Fuentes, J., 2018a. Development, characterization and test of an ultrasonic vibration-assisted ball burnishing tool. J. Mater. Proc. Technol. 257, 203-212.

Jerez-Mesa, R., Landon, Y., Travieso-Rodriguez, J.A., Dessein, G., Lluma-Fuentes, J., Wagner, V., 2018b. Topological surface integrity modification of AISI 1038 alloy after vibration-assisted ball burnishing. Surf. Coat. Technol. 349, 364-377.

Langenecker, B., 1966. Effects of ultrasound on deformation characteristics of metals. Son. Ultrason. IEEE Trans. 13 (1), 1-8.

Lee, S., Loh, N., 1996. Computer-integrated ball burnishing of a plastic-injection mould cavity insert. J. Mater. Proc. Technol. 57 (1), 189-194.

Prevey, P.S., 1986. X-Ray Diffraction Residual Stress Techniques. ASM Handbook, vol. 10. pp. 380-392.

Prevéy, P.S., Hornbach, D., Jacobs, T., Ravindranath, R., 2002. Improved Damage Tolerance in Titanium Alloy Fan Blades With Low Plasticity Burnishing. Retrieved from:. DTIC Technical Report. http://www.dtic.mil/docs/citations/ADA444609.

Shepard, M.J., Prevey, P.S., Jayaraman, N., 2004. Effects of Surface Treatment on Fretting Fatigue Performance of Ti-6Al-4V. Retrieved from:. DTIC Technical Report. http:// www.dtic.mil/docs/citations/ADA430663.

Shiou, F.J., Chen, C.H., 2003. Freeform surface finish of plastic injection mold by using ball burnishing process. J. Mater Proc. Technol. 140 (1), 248-254.

Travieso-Rodriguez, J.A., Dessein, G., Gonzalez-Rojas, H.A., 2011. Improving the surface finish of concave and convex surfaces using a ball burnishing process. Mater. Manuf. Proc. 26 (12), 1494-1502.

Travieso-Rodriguez, J.A., Gomez-Gras, G., Dessein, G., Carrillo, F., Alexis, J., Jorba-Peiro, J., Aubazac, N., 2015a. Effects of a ball-burnishing process assisted by vibrations in G10380 steel specimens. Int. J. Ad. Manuf. Technol. 81 (9-12), 1757-1765.

Travieso-Rodriguez, J.A., Gomez-Gras, G., Jorba-Peiro, J., Carrillo, F., Dessein, G., Alexis, J., Gonzalez-Rojas, H., 2015b. Experimental study on the mechanical effects of the vibration-assisted ball-burnishing process. Mater. Manuf. Proc. 30 (12), 1490-1497.

Ulutan, D., Ozel, T., 2011. Machining induced surface integrity in titanium and nickel alloys: a review. Int. J. Mach. Tool. Manu. 51 (3), 250-280. 